\title{
ОСОБЕННОСТИ ПРИВЛЕЧЕНИЯ ИНВЕСТИЦИЙ В ИННОВАЦИОННУЮ ДЕЯТЕЛЬНОСТЬ ФАРМАЦЕВТИЧЕСКИХ КОМПАНИЙ В РОССИИ
}

\author{
(C) 2021 Ганеев Азат Мулланурович \\ научный сотрудник \\ Институт Экономики РАН, Россия, Москва \\ E-mail: Azat.g@rambler.ru
}

В данной статье рассматривается современное состояние рынка фармацевтической продукции и инновационной деятельности фармацевтических компаний России. Автор анализирует механизм привлечения инвестиций с применением форм и механизмов ГЧП с целью инновационного развития фармацевтической промышленности России.

Ключевые слова: инновации, инвестиции, фармацевтическое производство

Сфера здравоохранения - одна из наиболее активно развивающихся и инновационных в современном мире. Наиболее крупным сегментом сферы здравоохранения является сектор фармацевтической продукции. По данный исследования Evaluate, продажи лекарственных препаратов в мире за 2020 год достигли \$900,7 млрд., увеличившись на 3\% в сравнении с 2019-м*.

Сфера здравоохранения занимала второе место в 2017 г. среди 2500 компаний мира, вкладывающих наибольшие финансовые ресурсы на НИОКР. В 2016 г. объем расходов на исследования и разработки только европейских и американских компаний сферы здравоохранения составил соответственно 41 и 62,9 млрд. евро ***.

Лидерами по объему вложений в исследования и разработки среди фармацевтических компаний являются: «Novartis», «Roche», «Merck\&Co.», «Johnson\&Johnson», «Pfizer», «Sanofi». Так в 2016 г. бюджет на НИОКР швейцарской компания «Novartis» составил 11,2 млрд. долл. Швейцарская Roche затратила 10,7 млрд. долл., а американская «Johnson\&Johnson» 10,2 млрд. долл.****

Рынок фармацевтической продукции в России также имеет тенденцию к росту. По данным DSM Group, оборот фармацевтических компаний с июня 2020 года по июнь 2021 года увеличился на 9\%, при этом оборот государственных закупок вырос на 30,7\%. Данные Росстата также это подтверждают - объем рынка лекарственных препаратов в августе 2021 года достиг 50,7 млрд. руб., что на $32 \%$ больше, чем годом ранее

Российские фармкомпании стремятся к инновационному развитию и увеличивают объем инвестиций в разработки оригинальной продукции. Например, компания «Петровакс» в 20202021 годах потратила более 1 млрд. руб. на исследования и разработку собственных продуктов. Объем инвестиций $3 \mathrm{AO}$ «Биокад» в научные исследования в 2021 году составил более 6,5 млрд. руб., это более чем вдвое больше затрат, чем в 2020 году. Компания «Нанолек» инвестировала на НИОКР в 2021 году свыше 220 млн. руб.****** Конечно, объем инвестиций значительно ниже, чем у зарубежных компаний, однако тенденция к росту позитивная.

В то же время, согласно отчету Deloitte, фармацевтические производители столкнулись с проблемой снижения показателя окупаемости инвестиций в исследования и разработки. С 2010 г. по 2017 г. показатель уменьшился с $10,1 \%$ до $3,7 \%$ соответственно. А стоимость создания и выхода на рынок новых лекарственных препаратов значительно возрастает: с 1,2 млрд. долл. в 2010 г. до почти 2 млрд.

\footnotetext{
* https://zdrav.expert/index.php/Статья: Фармацевтический_мировой_рынок

** Альтернативные стратегии инвестициям в корпоративные НИОКР (на примере глобальной фарминдустрии) Ерёмченко О.А. // Экономика науки. 2018. Т. 4. № 4. С. 310.

****https://www.vedomosti.ru/business/articles/2016/06/22/646274-rossiiskie-farmkompanii-razi-uvelichivayuttrati-klinicheskie-issledovaniya

**** https://www.finam.ru/analysis/newsitem/pyat-kompaniiy-rossiiyskoiy-farmy-kotoryiy-izvlekli-polzu-izcovid-19-20211110-194500/

****** https://tass.ru/ekonomika/13226925
} 
долл. в 2017 г.* Также по данным компании Roland Berger, расходы на исследования и разработки возросли более чем на 80\%, при этом количество зарегистрированных новых продуктов сократилось на $43 \%$ **.

В связи с этим растет необходимость привлечения инвестиций для создания новых продуктов и дальнейшего развития фармацевтических компаний, поскольку производителям все сложнее вести разработки инновационной продукции только за счет собственных средств.

Одним из наиболее перспективных направлений привлечения инвестиций в инновационную деятельность предприятий является активное применение форм и механизмов государственно-частного партнерства.

А.Г.Зельднер определяет государственночастного партнерства как «систему организационно-экономических отношений, предполагающую закрепление на контрактной основе прав и ответственности органов власти и бизнеса за совместное использование инвестиционных и других ресурсов, паритетное разделение рисков и прибыли, достижение конечных результатов при реализации крупных инфраструктурных проектов, а также перераспределение правомочий собственности и социализацию общественных отношений» ***.

Инновационная деятельность требует больших финансовых затрат и длительных сроков реализации для создания, внедрения продукта в производство и вывода на рынок. Это создает значительные риски для бизнеса. ГЧП позволяет значительно снизить вероятность неудачи, предоставляя определенные гарантии для частного партнера со стороны государства, а также предполагает вклад в проекты от государственного партнера.

Концессионные соглашения все чаще используются для проектов с применением инновационных технологий. На конкурсной основе определяется частный партнер концессионного соглашения, обязующийся по договору вкладывать ресурсы в строительство или ремонт, а также оснащение всем необходимым оборудованием объекта концессии, одновременно с этим получая право на управление им на срок согласно соглашению и право на оказание платных ус- луг населению для возврата вложенных средств и извлечения прибыли. Так с 2018 года активно внедряется система «умных» платных городских парковок. Например, компания «Городские парковки» заключила концессионное соглашение с муниципалитетом в Воронеже на обслуживание 6 тыс. парковочных мест. Контроль осуществляется с помощью 57 камер SOVA и десяти специальных автомобилей.

Еще одной из многообещающих форм государственно-частного партнерства стало Соглашение о защите и поощрении капиталовложений (СЗПК), созданное законом в 2020 году. Согласно закону, инвестор получает гарантии сохранения всех условий налогового режима и землепользования, а также частному партнеру возможно предоставление субсидии на строительство инфраструктуры. В зависимости от объемов привлеченных инвестиций срок длительности проекта может варьироваться - от 6 до 20 лет. Минимальный объем инвестиций 250 млн. руб.

СЗПК привлекателен как для российских, так и для иностранных инвесторов, поскольку в условиях внешней и внутренней экономической нестабильности гарантирует неизменность условий соглашения вне зависимости от возможных изменений.

Так, например, в рамках СЗПК планируется создание группой компаний «Р-Фарм» высокотехнологичного предприятия по производству вакцины от коронавируса Спутник V в Москве и Ростове (Ярославская обл.). Заявленный объем инвестиций - 8,57 млрд. руб.

Долгосрочность проектов и условий их осуществления является одним из главных его преимуществ. Создание высокотехнологичных производств требует значительных капиталовложений и подразумевает более длительный срок окупаемости, что вызывает повышенные риски для частного партнера. СЗПК дает четкие и неизменные правила осуществления деятельности и позволяет повысить уровень надежности партнерства и доверия к проекту.

В 2014 году был подписан закон, создавший специальный инвестиционный контракт (СПИК) - новую форму ГЧП, направленную на привлечение инвестиций в промышленное про-

\footnotetext{
* https://pharmvestnik.ru/content/news/analitiki-otmechajut-tendentsiju.html

** https://www.vedomosti.ru/business/articles/2013/01/17/farmacevty_u_obryva

*** Зельднер, А.Г. ГЧП - мейнстрим современной российской экономики. // Мир перемен. - 2014. - № 1 . С. $140-143$.
} 
изводство. Подписание данного контракта закрепляет за частным партнером обязательства по созданию или модернизации и (или) освоению производства промышленной продукции на территории России, а Российская Федерация или субъект РФ предоставляет и гарантирует инвестору положенные по закону льготы и преференции (льготы по налогам, гарантии сохранения условий налогового режима, возможность предоставления субсидий, привилегии статуса российского продукта).

Законодательство, регулирующее СПИК в 2019 году было значительно изменено: увеличен срок заключения СПИК, вводится конкурсный принцип отбора проектов, удален порог инвестиций. Изменения применяются только к новым проектам СПИК 2.0.

Но самым важным нововведением стало введение обязательного применения современной технологии в разработке или в производственном процессе проекта, представленного на конкурсный отбор. Технология должна присутствовать в перечне современных технологий, устанавливаемом постановлением правительства. СПИК становится инструментом привлечения инвестиций в разработку и производство только инновационной продукции, что, безусловно, должно привлечь в новые проекты высокотехнологичные предприятия и финансы крупных инвесторов, рассчитывающих на большие прибыли и имеющих возможность вкладывать на долгосрочную перспективу. В то же время необходимо понимать, что СПИК должен быть привлекательным для бизнеса и предлагать необходимые для них льготы и преференции в соответствии с текущей экономической ситуацией.

Уже начали появляться интересные проекты СПИК 2.0 с участием фармацевтических компаний. Например, Скопинский фармацевтический завод, совместно с Министерством промышленности и торговли России, а также руководством Рязанской области подписали в октябре 2021 года СПИК о создании проекта, в реализации которого будут применяться технологии производства готовой лекарственной формы различных ингибиторов протеинкиназ (препараты для онкологических заболеваний) и технологии производства оборудования визуализации тканей для диагностики онкологических заболеваний. Заявленный объем вложений в проект - 3,6 млрд. руб.

Целью экономической политики государства, на наш взгляд, должно стать качественное развитие фармацевтической промышленности России устремленное, прежде всего, на создание, внедрение отечественных инновационных лекарственных разработок, с применением механизмов ГЧП.

В условиях возрастания стоимости исследований и разработки оригинальной фармацевтической продукции, а также тяжелой внешнеполитической и внешнеэкономической обстановки использование форм ГЧП способствует в поиске источников инвестиций на длительные сроки, формирует условия для создания, привлечения и внедрения современных технологий в промышленное производство России, создает места для высококвалифицированных работников. На наш взгляд, ГЧП должно стать одним из ключевых государственных инструментов для формирования условий и благоприятной среды для создания и роста инновационных производств, для повышения конкурентоспособности промышленности и качественного развития экономики России.

\section{Библиографический список}

1. Зельднер А.Г. ГЧП - мейнстрим современной российской экономики.// Мир перемен. 2014. № 1. С. 140-143.

2. Ерёмченко О.А. Альтернативные стратегии инвестициям в корпоративные НИОКР (на примере глобальной фарминдустрии) // Экономика науки. 2018. Т. 4. № 4. С. 310-317.

3. https://zdrav.expert/index.php/Статья: Фармацевтический_мировой_рынок

4. https://www.vedomosti.ru/business/articles/2016/06/22/646274-rossiiskie-farmkompanii-razi-uvelichivayuttrati-klinicheskie-issledovaniya

5. https://www.finam.ru/analysis/newsitem/pyat-kompaniiy-rossiiyskoiy-farmy-kotoryiy-izvlekli-polzu-izcovid-19-20211110-194500/

6. https://tass.ru/ekonomika/13226925

7. https://pharmvestnik.ru/content/news/analitiki-otmechajut-tendentsiju.html

8. https://www.vedomosti.ru/business/articles/2013/01/17/farmacevty_u_obryva 